\title{
Barriers to Using Balance and Gait Assessment Tools by Physical Therapists in Patients with Neurological Impairments: A Systematic Review
}

Ho Young Jang ${ }^{1}$, You Lim Kim ${ }^{1}$, Jung Lim $\mathrm{Oh}^{2}$ and Suk Min Lee ${ }^{1^{*}}$

${ }^{1}$ Department of Physical Therapy, Sahmyook University, 26-21, Gongneung2-dong, Nowon-gu, Seoul, 139-742, Republic of Korea

${ }^{2}$ Department of Physical Therapy, Daewon University College, 316, Daehak Road, Jecheon City, Chungbuk Province, 390-702, Republic of Korea

"Corresponding author: Suk Min Lee, Department of Physical Therapy, Sahmyook University, 26-21, Gongneung2-dong, Nowon-gu, Seoul, 139-742, Republic of Korea, Tel: +82-2-3399-1632; E-mail: leesm@syu.ac.kr

Received date: August 2, 2017; Accepted date: August 10, 2017; Published date: August 15, 2017

Copyright: ( 2017 Jang HY, et al. This is an open-access article distributed under the terms of the Creative Commons Attribution License, which permits unrestricted use, distribution, and reproduction in any medium, provided the original author and source are credited.

\begin{abstract}
Introduction: The balance disability and pathological gait caused by neurological impairments deter activities of everyday living and social participation, deteriorate the quality of life, and increase the risk of falling. Physical therapeutic intervention plays a critical role in improving the balance disability and pathological gait. For effective physical therapy, accurate assessment of a patient is a priority.
\end{abstract}

Objective: This study aimed to identify the barriers regarding the use of the balance and gait assessment tests in patients with neurological impairments.

Method: Two reviewers used Electronic databases (Cochrane Library, MEDLINE, PEDro and RISS) to assess the titles and abstracts from the literature published until Dec. 2016 with the use of keywords, including "balance or posture or postural control or postural stability", "gait or walking or locomotion or ambulation", "test or assessment or measurement or outcome measure or assessment tool or measurement tool", "barriers", and "facilitators", read the full texts of identified articles, selected the publications related to the purpose of our study, and then analyzed materials from the literature.

Result: Independent reviewers and one analyst selected six materials from the literature relevant to the purpose of our study, and identified several barriers to using the balance and gait assessment tools by physical therapists, including therapists and patients' individual factors (lack of knowledge, low priority, and patients' functional ability), environmental factors (time, cost, space, and low organizational support), and measure-specific factors of the assessment tools (reliability, validity, and assessment tools appropriate for population).

Conclusion: Our study revealed the barriers to the use of the balance and gait assessment tool. Overcoming the barriers is essential to make it possible for physical therapists to efficiently use the tool for balance and gait assessment.

Keywords: Physical therapist; Neurological impairment; Balance; Gait; Assessment; Barriers

\section{Introduction}

Balance and gait are the basic abilities of physical activity required to perform activities of everyday life and social participation. Balance is the ability to control the center of mass relative to the base of support [1], to maintain a posture without falling, to achieve a motion in the stable condition, or to restore the body stability after external perturbation. It was reported that balance was influenced by the motor and sensory systems, and the physical properties of the individual [2]. Gait uses a repetitious sequence of limb motion to move the body forward while simultaneously maintaining stance stability, and is divided into stance phases and swing phases which are more specifically classified into Initial contact, Loading response, Mid stance, Terminal stance, Pre swing, Initial swing, Mid swing, and Terminal swing [3]. Balance and gait are influenced by the harmonized inherent action of the musculoskeletal and the neuromuscular systems and external environmental factors such as the shoe type, walking surface, lighting, the use of an assistive device, and gravity.

Patients with neurological impairments including stroke, traumatic brain injury, spinal cord injury, cerebral palsy, and Parkinson's disease, those with musculoskeletal system impairments including fracture, amputation, arthritis, and polio, those with medical diseases including diabetes, heart disease, and respiratory disease, and elderly persons experience changes in their balance disability, pathological gait, and gait pattern. These disabilities deter activities of everyday life and social participation. As a result, their quality of life deteriorates, and the risk of falling increases [4-12].

Physical therapy is a method to improve the balance disability and pathological gait and enhance the physical abilities. Intervention techniques such as neurophysiological approaches (Bobath), moving platform, biofeedback, electrostimulation, physical fitness training, high-intensity therapy, repetitive task-specific training, gait training using visual cues, treadmill training plus body weight support, roboticassisted body weight supported treadmill training and aquatic gait training are applied [13-17]. 
To render a physical therapy course effective, it is essential to accurately assess the patient's condition. Assessment is required to identify the causes of balance and gait problems, establish a treatment plan, and predict the outcome of the therapy. In addition, it helps provide the information necessary to educate patients and their caregivers and to equip them with confidence. Furthermore, assessment enables rehabilitation experts to share information, and is a critical part of evidence-based practice [18-20]. There are various methods of assessing the balance and gait ability of the patients with neurological impairments. For example, Romberg test, Single-Leg Stance test, Step test, Functional Reach test, 10 meter walk test, 6 minute walk test, and timed up \& go (TUG) test are assessment methods based on functional performance; Berg balance scale (BBS), postural assessment scale for stroke patients (PASS), activities-specific balance confidence $(\mathrm{ABC})$ scale, motor assessment scale (MAS), trunk impairment scale (TIS), Brunel balance assessment (BBA), Fugl-Meyer assessment (FMA), Dynamic Gait Index (DGI), Rivermead Mobility Index (RMI), Functional Ambulation Classification (FAC), Functional Independent Measure (FIM), Chedoke-McMaster Stroke Assessment, and Balance evaluation systems test (BESTest) are methods using the assessment tool of ordinal scale; and there are other methods using tooled measurement tools, such as the body control ability for postural sway, weight distribution, and external perturbation, and the kinetic or kinematic based tools [3,21-35].

These numerous assessments are used for academic or clinical purposes; therefore, it is difficult for therapists to apply an assessment method properly in line with a patient's functional level [36,37]. Van Peppen et al. found that, changing routines, time investment and financial compensation constituted significant barriers to assessment in a clinical setting [38]. In a different study, the lack of knowledge about assessment tools was the main barrier to balance and gait assessment $[39,40]$. In other studies, the floor \& ceiling effect of assessment tools make it difficult to assess patients with various physical activity levels [41], and assessment methods using equipment are limited owing to spatial restriction, difficult security of experts, and expensive equipment [23]. Assessment tools are not equally recognized among therapists owing to disparate medical insurance systems among countries, the lack of time caused by busy clinical settings, and various education system worldwide [42]. These barriers make it difficult for therapists to apply appropriate assessment methods to clinics in relation to patient's functional levels. Nevertheless, there is not sufficient systematic research regarding the potential barriers to the assessment of balance and gait in patients with neurological impairments.

Therefore, this study aims to identify, through a systematic review of the literature the barriers faced by physical therapists working in a clinical setting while performing balance and gait assessments, and to develop a strategy to overcome these barriers. The result of our study will contribute to the more effective use of assessment tools by physical therapists.

\section{Method}

This study was approved by the Institutional Review Board of Sahmyook University in January 2017.

For a systematic review, studies were searched using, Cochrane Library, MEDLINE, PEDro and RISS electronic databases to identify the materials published from December 2011 to December 2016. Various search keywords were used, including, "balance or posture or postural control or postural stability" AND "gait or walking or locomotion or ambulation" AND "test or assessment or measurement or outcome measure or assessment tool or measurement tool" AND "barriers" AND "facilitators". The searched keywords were divided into four work groups: balance group, gait group, assessment group, and barriers group. Two reviewers (Jang HY, Kim YL) entered more than two word-groups to search for the titles and abstracts from the materials found, for instance, "Balance and Gait", "Balance and Walking", "Balance and Assessment and Barriers", or "Balance and Gait and Assessment and Barriers". To select studies appropriate for our study, the reviewers read the full texts checked the references from selected articles and subsequently. read the full texts from the selected references. The reviewers agreed in the selection publications that met the purpose of our study. Data were analyzed by one analyst (Oh JL), who classified the selected materials based on methodology and results. 9 full-text articles excluded with reasons (same author or barriers factor unclear). Subsequently, two reviewers and one analyst completed the analysis (Figure 1).

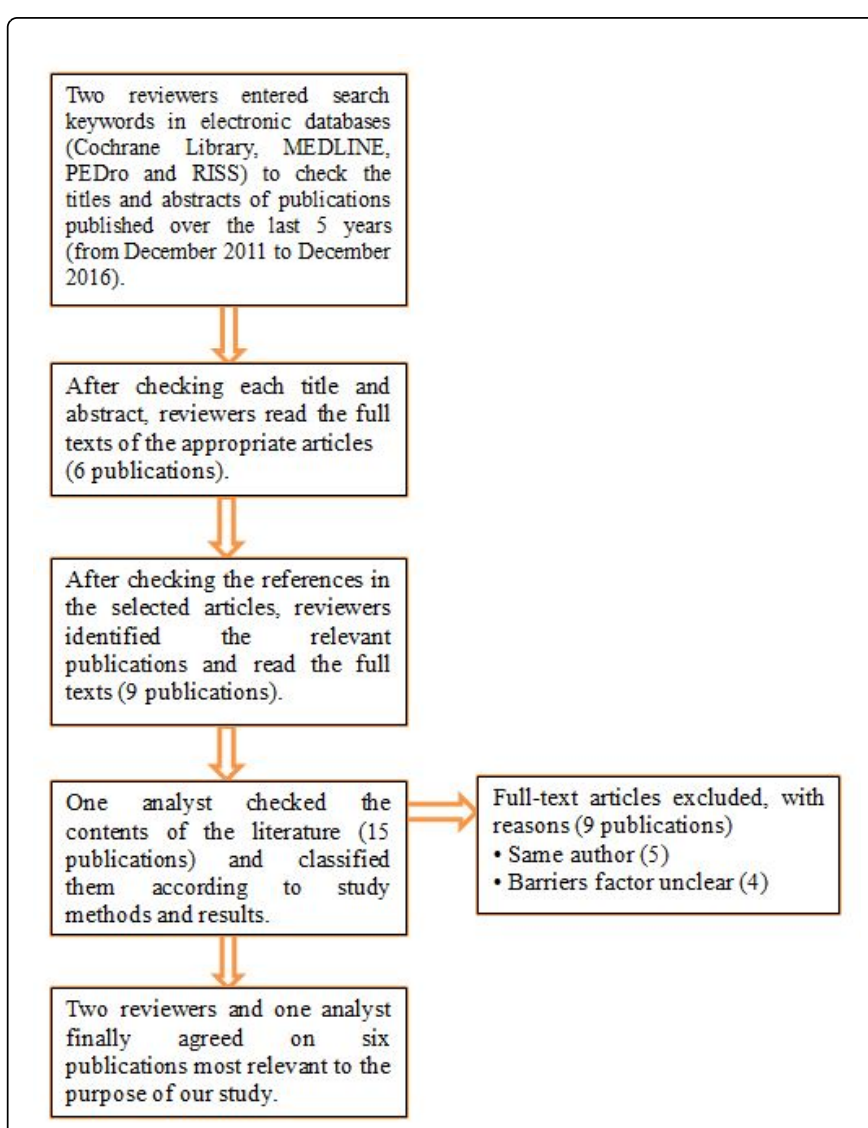

Figure 1: Process of the study.

\section{Results}

Each reviewer checked the titles and abstracts from the selected studies, read the full texts from 15 publications, selected six articles relevant to the purpose of our study, and subsequently identified barriers to physical therapists' balance and gait assessment in patients with neurological impairments (Table 1). 


\begin{tabular}{|l|l|l|}
\hline Author & Research Method & Barriers \\
\hline $\begin{array}{l}\text { Sibley KM and Salbach NM } \\
\text { (2015) }\end{array}$ & Case report & $\begin{array}{l}\text { Lack of knowledge } \\
\text { Low priority } \\
\text { Lack of time } \\
\text { Tools not appropriate } \\
\text { for population }\end{array}$ \\
\hline Pattison KM, et al. (2015) & $\begin{array}{l}\text { Qualitative descriptive } \\
\text { study } \\
\text { (28 Physical therapists) }\end{array}$ & $\begin{array}{l}\text { Validity and reliability } \\
\text { Cost } \\
\text { Space }\end{array}$ \\
\hline $\begin{array}{l}\text { Duncan E and Murray J J } \\
\text { (2012) }\end{array}$ & Systematic review & $\begin{array}{l}\text { Knowledge } \\
\text { Low organizational } \\
\text { support } \\
\text { Time }\end{array}$ \\
\hline McGinnis PQ, et al. (2009) & $\begin{array}{l}\text { Qualitative design } \\
\text { (11 Physical therapists) }\end{array}$ & $\begin{array}{l}\text { Knowledge } \\
\text { Time }\end{array}$ \\
\hline $\begin{array}{l}\text { Tyson SF and Connell LA } \\
\text { (2009) }\end{array}$ & Systematic review & $\begin{array}{l}\text { Validity and reliability } \\
\text { Lack of time } \\
\text { Cost } \\
\text { Space }\end{array}$ \\
\hline Van Peppen, et al. (2008) & $\begin{array}{l}41 \text { ltem Survey } \\
\text { (167 Physical therapist) }\end{array}$ & $\begin{array}{l}\text { Changing routines } \\
\text { Time investment } \\
\text { Financial } \\
\text { compensation }\end{array}$ \\
\hline
\end{tabular}

Table 1: Six publications relevant to the objective of this study.

Sibley and Salbach had identified significant barriers to balance and gait assessment. Based on the study regarding the Canadian physical therapists' perceptions and use of balance and gait assessment $[39,40,43]$, the authors suggested that individual (lack of knowledge and low priority), environmental (lack of time), and measure-specific (tools not available, tools not appropriate for population) factors contribute as barriers to balance assessment; reliable and valid measures, lack of time, uncertainty that measures are useful to quantify severity of deficit, and beliefs that measures do not reflect the home or community environment, are difficult to administer, lack sensitivity to change, are a low priority and lack normative values as gait assessment [44].

Pattison conducted a qualitative descriptive study regarding the factors that influence the use of standardized gait assessment tools by interviewing 28 physical therapists. As a result, he suggested that familiarity, patient, colleagues, guidelines, ease of use, time, space, validity, reliability, and cost are contributing factors that influence the use of gait assessment tools in patients with stroke [45].

Duncan and Murray examined the barriers and facilitating factors in routine outcome measurement with allied health professionals and identified four higher level issues: first, the therapists' knowledge, education, and value recognition of measurement tools; second, the support and priority for measurement tools; third, practical considerations including time and cost; fourth, patient considerations [46].

In a qualitative study with 11 participating physical therapists, McGinnis analyzed the factors influencing the selection of a balance assessment tool. According to their study, the barriers to the use of assessment tools were time required for initial examination and that required to complete tests as physical therapists' view of constraints; age, diagnosis, and functional ability as patient factors; screening and diagnoses as physical therapists' intended use of information; formal knowledge and practical experience as physical therapists' knowledge; and other sources of information (colleagues, the literature, continuing education, etc.) [47].

Tyson studied how to perform balance and gait assessment in a clinical setting. He determined barriers to assessment in the categories of psychometrics properties and clinical utility. Psychometrics properties included reliability, validity and sensitivity. Clinical utility included time, cost, specialist equipment, training to use, and tool portable [48].

Van Peppen conducted a questionnaire- based survey consisting of 41 questions with 167 physical therapists. According to the survey, changing routines, time investment and financial compensation were recognized as barriers to the use of assessment tools in a clinical setting [49].

Based on the results of the data analysis, we found that three categories were significant. First, therapists and patients' individual factors that included lack of knowledge, low priority, and patients' functional ability. Second, environmental factors that included lack of time, excessive or low assessment cost, spatial restriction, and lack of organizational support. Third, measure-specific factors that included reliability, validity, and assessment tools appropriate for population. In addition, the existence of numerous assessment tools became a barrier to the use of assessment tools (Figure 2).

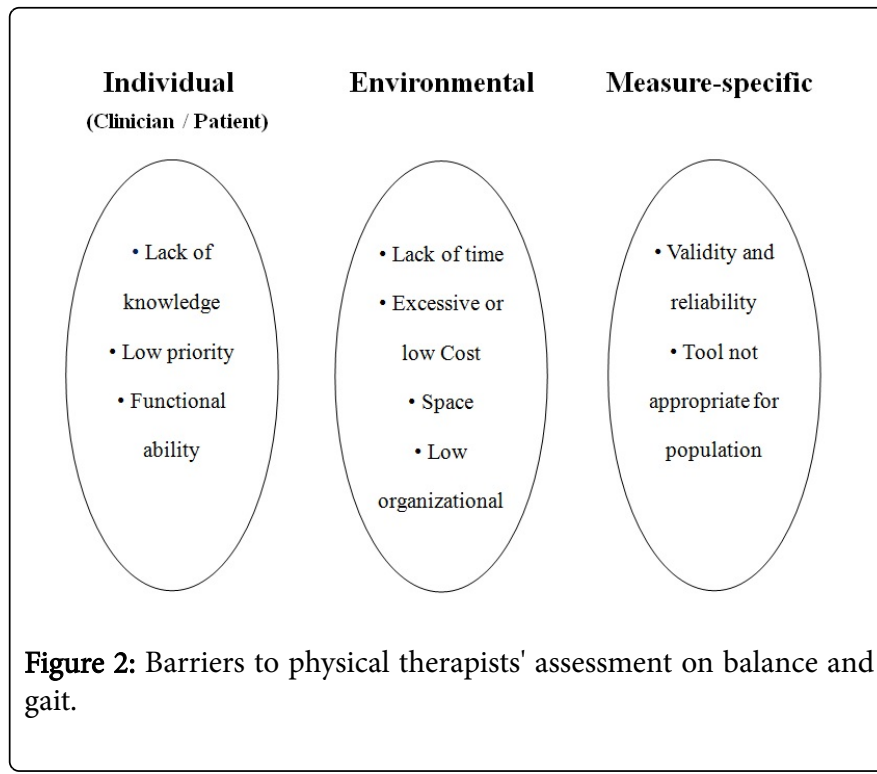

\section{Discussion}

The balance disability and pathological gait caused by neurological impairments deter activities of everyday living and social participation, lower quality of life, and increase the risk of falling [10-12]. Physical therapeutic intervention plays a critical role in improving the balance disability and pathological gait [13]. For effective physical therapy, accurate assessment of a patient is a priority [18-20]. Unfortunately, barriers to balance and gait assessment make it difficult for therapists to use assessment tools. Therefore, these researchers conducted a systematic review of the literature on the barriers to physical therapists' 
balance and gait assessment in patients with neurological impairments in a clinical setting, and devised a strategy for overcoming them.

\section{Barriers to balance and gait assessment}

Independent reviewers checked the titles and abstracts from published articles, reviewed the full text from 15 publications from the literature, and selected and analyzed six publications relevant to the purpose of this study. As a result, we identified barriers classified into three categories: individual factors, environmental factors, and measure-specific factors. Individual factors were divided into therapists' and patients-related barriers, and included lack of knowledge about assessment tools, low priority, and patients' functional ability. Regarding to environmental factors, barriers included lack of time, excessive or low assessment cost, spatial restriction, and low organizational support. Regarding measurespecific factors, barriers were reliability and validity of assessment tools, and the application of an assessment tool appropriate for population [38,44-48].

\section{Individual factors}

Individual factors were analyzed in accordance with the therapist's or patients' view. Regarding therapists', barriers to the use of assessment tools included lack of knowledge and low priority $[44,46,47]$. Sibley and Salbach examined the Canadian physical therapists' recognition of balance and gait assessment and actual conditions, and reported that lack of knowledge was the most critical barrier to the use of assessment tools [44]. According to a systematic literature review by Duncan and Murray, 11 of 15 publications revealed that therapists' knowledge was related to their use of assessment tools [46]. A study by McGinnis et al. also reported that therapists knowledge was a critical determinant in the application of an assessment tool [47]. Sibley and Salbach reported that therapists' low priority of assessment tools was also a barrier [44]. Regarding patients', consideration factors in the use of assessment tools included age, diagnosis, and functional ability [47], and barriers were patients' physical ability for assessment, linguistic communication, and ethical or cultural barriers [46].

\section{Environmental factors}

In a clinical setting, barriers included lack of time, too high or too low assessment cost, spatial restriction, and low organizational support [38,44-48]. All six publications that these researchers identified explained clinical environmental barriers. Among the barriers, lack of time was described in all articles. Previous studies revealed that, lack of time was a critical barrier in a clinical setting. The time of initial examination, and the time of completion of the test were critical factors that determined an assessment tool $[46,47]$. In addition, in a busy clinical setting with too many patients, time limitations impair proper assessment [46]. In three studies, too high or too low assessment cost was identified as barrier $[38,46,48]$. In other articles, cost was a low priority in decision-making [45]. This seems to be related to disparities in medical insurance systems among countries. Spatial restriction and low organizational support were also barriers in a clinical setting $[45,46,48]$.

\section{Measure-specific factors}

Regarding measure-specific factors, barriers were reliability and validity of assessment tools, and recognition of an assessment tool appropriate for population $[44,45,46,48]$. Subjective assessment can yield measurement errors therefore, it is necessary to use assessment tools with reliability and validity [44-46,48]. In addition, it was found that one barrier was the selection of an assessment tool appropriate for population $[44,46,48]$. For accurate assessment, it is important to select an assessment tool appropriate for a patient's physical ability however, this is challenging.

In addition to those barriers, the fact that there are numerous assessment tools used for clinical or academic purposes, was a barrier. In some countries, multiple assessment tools were recommended for balance and gait assessment.

\section{Efforts to overcome barriers}

To overcome these barriers, it is necessary to provide better education and suggest standardized clinical environmental criteria to properly use assessment tools with reliability and validity, understand the various medical insurance systems among countries and make changes, and propose unified guidelines to select only one out of numerous assessment tools.

It is important to use an assessment tool with reliability and validity in patients with neurological impairments to achieve proper clinical assessment. In fact, assessment tools are inherently limited. Therefore, it is necessary to select a wide range assessment tool [44], or it may be more efficient to use multiple assessment tools in a way of using both PASS and ABC scale to improve the limited range of BBS, than to use only one assessment tool [41]. In Tyson's study regarding the selection of a balance and gait assessment tool for patients with neurological impairments, functional and ordinal-scale assessment tools were recommended $[48,49]$. In a recent systematic review aimed at enhancing the general use of assessment tools, education for the use of assessment tools has been emphasized [50]. It is also important to include reliability and validity of assessment tools when the tools are translated to a native language [51,52]. In addition, it is important to resolve the knowledge gaps between various university courses among countries [53].

To apply an assessment tool, it is significant to recommend standardized clinical environmental criteria appropriate for assessment. Time is the most significant barrier to the application of an assessment tool in a clinical setting. To address this issue, various assessment tools have been developed. In addition, in the country the number of patients that therapists care for during the day, is inversely correlated with the time they spend performing assessment. Therefore, it is necessary to make a change in the point [42]. Among countries, there are various medical insurance systems; thus, so there are various medical payments depending on the use of an assessment tool. Too high or too low assessment cost for therapists and patients is directly correlated with the use of an assessment tool [54]. Therefore, it is necessary to suggest a reasonable medical payment for therapist and patient assessment.

Guidelines that recommend one assessment tool appropriate for patients versus other assessment tools can be effective at overcoming barriers. However, in some countries, different assessment tools are recommended according to guidelines [48,49,55-57]. Therefore, it is necessary to develop a consensus regarding the use of only one assessment tool.

Our study has the following limitations. Although studies were selected through a review of the literature, only those published in English were considered. Hence, it was not possible to identify all 
relevant publications. The electronic databases were only limited to Cochrane Library, MEDLINE, PEDro and RISS. This study failed to review the literature published after December 2016, the literature not registered, and gray literature. Even though the reviewers and analyst were experts in this field, the process of agreeing and selecting six articles was subjective. Moreover, only one of the six publications was a systematic review, and the remaining were qualitative design and survey therefore, there was low objectivity.

\section{Conclusion}

In conclusion, essential barriers to the use of assessment tools were individual factors (lack of knowledge, low priority, and patients' functional ability), environmental factors (lack of time, too high or low assessment cost, spatial restriction, and organizational support), and measure-specific factors (reliability, validity, and an assessment tool appropriate for population). To overcome these barriers, it is necessary to provide education of standardized assessment, change of clinical settings and medical insurance systems, and to recommend appropriate guidelines. Thus, it is possible for physical therapists to perform balance and gait assessment efficiently and accurately. As part of the effort to overcome the barriers and make general use of assessment tools, it is necessary to conduct a comparative study regarding the different types of assessment education, clinical settings, medical insurance systems, and guidelines in various countries.

\section{References}

1. Shumway-Cook A, Woollacott MH (2007) Motor Control translating Research into Clinical Practice. 3rd ed. Philadelphia: Lippincott Williams \& Wilkins.

2. Pollock AS, Durward BR, Rowe PJ (2000) What is balance? Clin Rehabil 14: 402-406.

3. Perry J (1992) Gait Analysis: Normal and Pathological Function. Thorofare NJ: Slack.

4. Tyson SF, Hanley M, Chillala J, Selley A, Tallis RC (2006) Balance disability after stroke. Phys Ther 86: 30-38.

5. Basford JR, Chou LS, Kaufman KR, Bery RH, Walker A, et al. (2003) An assessment of gait and balance deficits after traumatic brain injury. Arch Phys Med Rehabil 84: 343-349.

6. Sturnieks DL, Tiedemann A, Chapman K, Murray SM, Lord SR (2004) Physiological risk factors for falls in older people with lower limb arthritis. J Rheumatol 31: 2272-2279.

7. Sturnieks DL, George R, Lord SR (2008) Balance disorders in the elderly. Clin Neurophysiology 38: 467-478.

8. Springer BA, Marin R, Cyhan T, Roberts H, Gill NW (2007) Normative values for the unipedal stance test with eyes open and closed. J Geriatr Phys Ther 30: 8-15.

9. Bohannon RW (1997) Comfortable and maximum walking speed of adults aged 20-79 years: reference values and determinants. Age and Ageing 26: 15-19.

10. WHO (2001) International Classification of Functioning Disability and Health. Geneve: ICF-introduction.

11. Mayo NE, Wood-Dauphinee S, Cote R, Durcan L, Carlton J (2002) Activity, participation, and quality of life 6 months poststroke. Arch Phys Med Rehabil 83: 1035-1042.

12. Guideline for the prevention of falls in older persons (2001) American Geriatrics Society, British Geriatrics Society, American Academy of Orthopaedic Surgeons Panel on Falls Prevention. J Am Geriatr Soc 49: 664-672.

13. Langhorne P, Coupar F, Pollock A (2009) Motor recovery after stroke: a systematic review. Lancet Neurol 8: 741-754.
14. Sidaway B, Anderson J, Danielson G, Martin L, Smith G (2006) Effects of long-term gait training using visual cues in an individual with Parkinson disease. Phys Ther 86: 186-194.

15. Behrman AL, Lawless-Dixon AR, Davis SB, Bowden MG, Nair P, et al. (2005) Locomotor training progression and outcomes after incomplete spinal cord injury. Phys Ther 85: 1356-1371.

16. T George Hornby, David HZ, Donielle C (2005) Robotic-assisted, body weight supported treadmill training in individuals following motor incomplete spinal cord injury. Phys Ther 85: 52-66.

17. Jung T, Ozaki Y, Lai B, Vrongistinos K (2014) Comparison of energy expenditure between aquatic and overground treadmill walking in people post-stroke. Physiother Res Int 19: 55-64.

18. Horak FB (1997) Clinical assessment of balance disorders. Gait Posture 6: 76-84.

19. Best R, Begg R (2006) Overview of movement analysis and gait features. In Computational Intelligence for Movement Science: Neural Networks and Other Emerging Techniques. Calgary, Idea Group Inc 1-69.

20. American Physical Therapy Association (2001) Guide to physical therapy practice. 2nd ed. Phys Ther 81: 9-746.

21. Tyson S, DeSouza L (2002a) A systematic review of methods to measure balance and walking post-stroke. Part 1: ordinal scales. Physical therapy reviews 7: 173-186.

22. Tyson S, DeSouza L (2002b) The measurement of balance and walking post-stroke. Part 2: Functional performance tests. Physical therapy reviews 7: 187-191.

23. Tyson S, Desouza L (2002c) The measurement of balance post-stroke. Part 3: Instrumented measurement tools. Physical therapy reviews 7: 231-241.

24. Duncan PW, Weiner DK, Chandler J (1990) Functional reach: a new clinical measure of balance. J Gerontol 45: M192-197.

25. Podsiadlo D, Richardson S (1991) The timed "Up \& Go": a test of basic functional mobility for frail elderly persons. J Am Geriatr Soc 39: 142-148.

26. Berg K (1989) Measuring balance in the elderly: preliminary development of an instrument. Physiotherapy Canada 41: 304-311.

27. Powell LE, Myers AM (1995) The Activities-specific Balance Confidence (ABC) Scale. J Gerontol A Biol Sci Med Sci 50a: M28-M34.

28. Benaim C, Perennou DA, Villy J (1999) Validation of a standardized assessment of postural control in stroke patients: the Postural Assessment Scale for Stroke Patients (PASS). Stroke 30: 1862-1868.

29. Carr JH, Shepherd RB, Nordholm L, Lynne D (1985) Investigation of a new motor assessment scale for stroke patients. Phys Ther 65: 175-180.

30. Verheyden G, Nieuwboer A, Mertin J (2004) The Trunk Impairment Scale: a new tool to measure motor impairment of the trunk after stroke. Clin Rehabil 18: 326-334.

31. Tyson SF, DeSouza LH (2004) Development of the Brunel Balance Assessment: a new measure of balance disability post stroke. Clin Rehabil 18: 801-810.

32. Finch E, Brooks D, Stratford PW, Mayo N (2002) Physical rehabilitation outcome measures. 2nd edition. Baltimore: Lippincott, Williams \& Wilkins.

33. Shumway-Cook A, Woollacott MH (1995) Motor Control: theory and practical applications. Baltimore: Williams \& Wilkins.

34. Collen FM, Wade DT, Robb GF, Bradshaw CM (1991) The Rivermead Mobility Index: a further development of the Rivermead Motor Assessment. Int Disabil Stud 13: 50-54.

35. Horak FB, Wrisley DM, Frank J (2009) The Balance evaluation systems test (BESTest) to differentiate balance deficits. Phys Ther 89: 484-498.

36. Berg K, Maki B, Williams J (1992) Clinical and laboratory measures of postural balance in an elderly population. Arch Phys Med Rehabil 73: 1073-1080.

37. Grimmer K, Bialocerkowski A, Kumar S, Milanese S (2004) Implementing evidence in clinical practice: the 'therapies' dilemma. Physiotherapy 90: 189-194 
Citation: Jang HY, Kim YL, Oh JL, Lee SM (2017) Barriers to Using Balance and Gait Assessment Tools by Physical Therapists in Patients with Neurological Impairments: A Systematic Review. J Clin Res Bioeth 8: 309. doi:10.4172/2155-9627.1000309

Page 6 of 6

38. Van Peppen RP, Maissan FJ, van Genderen FR, van DR, van Meeteren NL (2008) Outcome measures in physiotherapy management of patients with stroke: a survey into self-reported use, and barriers to and facilitators for use. Physiother Res Int 13: 255-270.

39. Salbach NM, Guilcher SJT, Jaglal SB (2011) Physical therapists' perceptions and use of standardized assessments of walking ability poststroke. J Rehabil Med 43: 543-549.

40. Sibley KM, Straus SE, Inness EL, Salbach NM, Jaglal SB (2013) Clinical balance assessment: perceptions of commonly-used standardized measures and current practices among physiotherapists in Ontario, Canada. Implement Sci 8: 33.

41. Blum L, Korner-Bitensky N (2008) Usefulness of the Berg balance scale in stroke rehabilitation: a systematic review. Phys Ther 88: 559-566.

42. Jang HO, Kim YL, Lee SM (2017) Perception and use of balance measures for stroke patients among physical therapists in South Korea. J Phys Ther Sci 29: 255-260.

43. Sibley KM, Straus SE, Inness EL, Salbach NM,Jaglal SB (2011) Balance assessment practices and use of standardized balance measures among Ontario physical therapists. Phys Ther 91: 1583-1591.

44. Sibley KM, Salbach NM (2015) Applying knowledge translation theory to physical therapy research and practice in balance and gait assessment case report. Phys Ther 95: 579-587.

45. Pattison KM, Brooks D, Cameron JI, Salbach NM (2015) Factors influencing physical therapists' use of standardized measures of walking capacity poststroke across the care continuum. Phys Ther 95: 1507-1517.

46. Duncan EA, Murray J (2012) The barriers and facilitatiors to routine outcome measurement by allied health professionals in practice: a systematic review. BMC health services research 12:96.

47. McGinnis PQ, Hack LM, Nixon-Cave K (2009) Factors that influence the clinical decision making of physical therapists in choosing a balance assessment approach. Phys Ther 89: 233-247.
48. Tyson SF, Connell LA (2009) How to measure balance in clinical practice. A systematic review of the psychometrics and clinical utility of measures of balance activity for neurological conditions. Clin Rehabil 23: 824-840.

49. Tyson SF, Connell LA (2009) The psychometrics properties and clinical utility of measures of walking and mobility in neurological conditions: a systematic review. Clin Rehabil 23: 1018-1033.

50. Colquhoun HL, Lamontagne ME, Duncan EA, Fiander M, Champagne C, et al. (2017) A systematic review of interventions to increase the use of standardized outcome measures by rehabilitation professionals. Clin Rehabil 31: 299-309.

51. Seo HD, Kim NJ, Chung YJ (2008) Reliability of the Korean version of the trunk impairment scale in patients with stroke. PTK 15: 87-94.

52. Jung HY, Park JH, Sim JJ (2006) Reliability test of Korean version of Berg balance scale. J Korean Acad Rehab Med 30: 611-618.

53. Kim K, Park RJ, Cho YH (2006) A study on the development of standard curriculum for physical therapy in Korea. J Kor Soc Phys Ther 18: 23-32.

54. Park HJ, Lee CHH, Cho SH (2000) Physical therapist's understanding and the usage of assessment tools for children with delayed development and cerebral palsy. KAUTPT 7: 1-21.

55. Stokes EK, O'Nell D (2008) Use of outcome measures in physiotherapy practice in Ireland from 1998 to 2003 and comparison to Canadian trends. Physiother Can 60: 109-116.

56. Sullivan JE, Crowner BE, Kluding PM (2013) Outcome measures for individuals with stroke: process and recommendations from the American Physical Therapy Association Neurology Section Task Force. Phys Ther 93: 1383-1396.

57. Kang TW, Oh DW (2013) Literature review of walking performance tests for people with post-stroke hemiparesis. Kor J Neural Rehabil 3: 28-40. 